\title{
СОЗДАНИЕ АВТОНОМНЫХ И СЕТЕВЫХ ЭНЕРГОТЕХНОЛОГИЧЕСКИХ КОМПЛЕКСОВ С ВОДОРОДНЫМ НАКОПИТЕЛЕМ ЭНЕРГИИ
}

\author{
А.А. Шевченко, главный инженер отдела водородной энергетики \\ Институт проблем машиностроения им. А.М. Подгорного НАН Украины, \\ 61046, ул. Пожарского 2/10, г. Харьков, Украина.
}

В статье проведен анализ энергетических возможностей альтернативных источников Украины. Рассмотрены проекты с применением водородных технологий, направленных на привлечение энергии Солнца в инфраструктуру энерготехнологических комплексов, в частности для заправки автомобильного транспорта, расположенных в зонах с высоким потенциилом солнечной радиащии. При эксплуатащии автономных заправочных станций, использующих в качестве источника энергии солнечную энергетическую станцию (СЭС), весьма вероятно возникновение нештатных ситуаций, обусловленных прекращением энергоснабжения (вследствие пасмурной погоды), либо аварийным выходом из строя отдельных элементов системы. В данном случае требуется обеспечить вывод ее из эксплуатации без потери технологических возможностей (работоспособности). С этой иелью необходимо предусмотреть включение в технологическую схему энерготехнологического комплекса дополнительного элемента, обеспечивающего работу блока в течение заданного времени, определяемого регламентом его эксплуатации. В качестве такого элемента предложена буферная система на основе водородного накопителя энергии. Современный уровень водородных технологий, которые реализуются в электрохимических установках, разработанных в Институте проблем машиностроения им. А. Н. Подгорного Национальной академии наук Украины (ИПМаш НАН Украины), позволяет производить и накапливать водород под высоким давлением, что исключает использование компрессорной техники.

Приведена принцииальная схема автономного солнечно-водородного энерготехнологического комплекса для заправки автомобильного транспорта.

Описаны особенности подключения солнечных батарей в составе энерготехнологического комплекса. Библ. 20, табл. 1 , рис. 6. Ключевые слова: альтернативные источники, энерготехнологический комплекс, водород, энергия солнца, водородный генератор.

\section{CREATION OF AUTONOMOUS AND NETWORK ENERGY-TECHNOLOGICAL COMPLEXES WITH A HYDROGEN STORAGE OF ENERGY}

\author{
A. Shevchenko, chief engineer of the hydrogen energy department \\ Institute of Mechanical Engineering A.M. Podgorny NAS of Ukraine, \\ 61046, st. Pozharsky 2/10, Kharkov, Ukraine.
}

\begin{abstract}
The article analyzes the energy potential of alternative sources of Ukraine. Projects using hydrogen technologies aimed at attracting solar energy to the infrastructure of energy technological complexes, in particular water desalination systems and for refueling vehicles located in areas with high solar radiation potential, are considered. During the operation of water desalination plants using a solar power station (SES) as an energy source, contingencies are very likely to arise due to either a power outage (due to cloudy weather) or an emergency failure of individual elements of the system. In this case, it is required to ensure its decommissioning without loss of technological capabilities (operability). For this purpose, it is necessary to provide for the inclusion in the technological scheme of the energy technological complex of an additional element that ensures the operation of the unit for a given time, determined by the regulations for its operation. As such an element, a buffer system based on a hydrogen energy storage device is proposed. The current level of hydrogen technologies that are implemented in electrochemical plants developed at the Institute of Mechanical Engineering named after A. N. Podgorny National Academy of Sciences of Ukraine (IPMash NAS of Ukraine) allows the production and accumulation of hydrogen under high pressure, which eliminates the use of compressor technology.

A schematic diagram of an autonomous solar-hydrogen energy-technological complex for refueling vehicles is given.
\end{abstract}

The features of connecting solar panels as part of the energy technology complex are described. Ref. 20, tab. 1, fig. 6.

Keywords: alternative sources, energy technology complex, hydrogen, solar energy, hydrogen generator. 


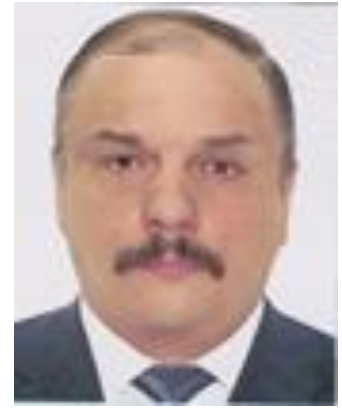

A.А. Шевченко

A. Shevchenko
Сведения об авторе: главный инженер отдела водородной энергетики.

Образование: Харьковский Национальный Аэрокосмический Университет им. Жуковского «ХАИ», факультет авиационных двигателей, специальность «Теплоэнергетика». Научная сфера: получение, хранение и использование водорода, возобновляемая энергетика.

Публикаци: 16 статей в научных изданиях Украины, 2 содержится в наукометрических базах Scopus и Web of Science; 7 патентов Украины на изобретение и 5 патентов Украины на полезную модель.

ORCID: 0000-0002-6009-2387

Контакты: +38 (057)3494782

e-mail: shevchenko84@ukr.net
Author information: Principal engineer of the hydrogen energy department.

Education: Kharkiv National Aerospace University Zhukovsky «KhAI», faculty of aviation engines, specialty «Heat engineering».

Scientific field: production, storage and use of hydrogen, renewable energy.

Publication: 16 articles in scientific journals of Ukraine, 2 contained in the scientometric database Scopus and Web of Science; 7 patents of Ukraine for an invention and 5 patents of Ukraine for a utility model.

ORCID: 0000-0002-6009-2387

Contacts: +38 (057) 3494782

e-mail: shevchenko84@ukr.net
Перечень использованных обозначений и сокращений: ФЭП - фотоэлектрический преобразователь;

АКБ - аккумуляторная батарея;

СЭС - солнечная энергетическая станция;

СВЗС - солнечно-водородная заправочная станция;

Введение. Для расширения масштабов использования возобновляемых видов энергии необходимо совершенствование процессов преобразования энергии и повышение техникоэкономических характеристик энерготехнологических систем, создаваемых на их основе. Одним из основных путей решения этой проблемы является повышение эффективности рабочих процессов во всех звеньях системы, как на стадии генерации энергии, так и при ее аккумулировании для обеспечения бесперебойного энергоснабжения технологических объектов. Украина обладает значительным потенциалом возобновляемых источников энергии, но на сегодня доля их использования в энергобалансе страны не существенна [1].

Учитывая ежегодную тенденцию к снижению стоимости использования альтернативной энергетики, благодаря совершенствованию технологических схем ее преобразования, можно дать положительный прогноз на значительное повышение вклада возобновляемой энергетики в энергетическую независимость и безопасность Украины [2].

Цель статьи. Для решения энергоэкологических вопросов Украины целесообразно повысить долю использования возобновляемых источников энергии путем создания автономных солнечно-водородных заправочных станций (CВ3С) на базе инновационных электрохимических технологий и фотоэлектрических преобразователей для обеспечения автомототранспорта экологически чистым топливом - водородом. Предусмотрено включение в технологическую схему энерготехнологического комплекса допол-
ЭТК - энерготехнологический комплекс;

ЭВД - электролизёр высокого давления;

ЭДС - электродвижущая сила.

нительных элементов, обеспечивающих его работу в течение заданного времени, определяемого режимом эксплуатации. В качестве такого элемента предложена буферная система накопления водорода, предназначенная для бесперебойного энергоснабжения, как при работе комплекса в нестационарных режимах, так и в случае аварийной остановки.

Потенциал солнечного излучения Украины. В последнее время интерес к вопросу использования солнечной энергии резко возрос. Этот источник относится к возобновляемым ресурсам и уделяемое ему внимание во всем мире заставляет рассмотреть его возможности отдельно. Потенциал использования солнечной энергии в Украине является достаточно высоким для широкого внедрения как тепло-, так и фотоэнергетического оборудования.

При прямом солнечном облучении элементов, изготовленных из полупроводникового материала кремния, возникает разность потенциалов на поверхности, т.е. наличие ЭДС.

Солнечная энергетика в Украине пока не получила широкого хозяйственного использования, однако предпосылки для этого есть. Она способна обеспечить экономию за год до 6 млн. т условного топлива. Потенциал ее развития обеспечивают собственная научная и промышленная базы, конструкторские бюро, проектирующие солнечные коллекторы, собственное производство моно- и поликристаллического кремния и др. Начиная с 2010 года, гелиоэнергетика получила широкое внедрение в Украине. 
Суммарное среднегодовое количество солнечной энергии, поступающей на 1 км$^{2}$ территории Украины, составляет почти 1070 кВт ч в се-

верной части страны и 1400 кВт · ч и выше в южных областях (рис.1).

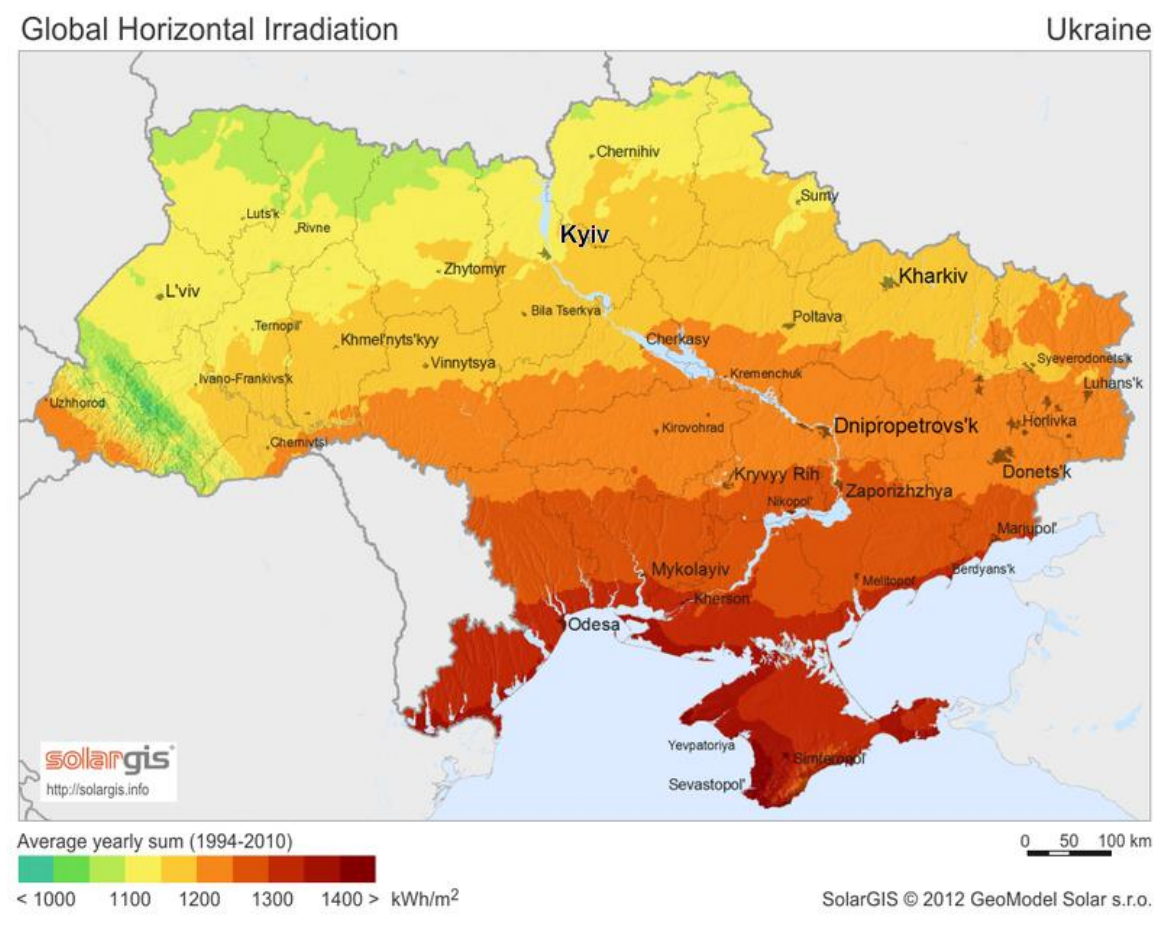

Рис. 1. Технический потенциал гелиоэнергетических ресурсов Украины для выработки электроэнергии.

Fig. 1. The technical potential of the solar energy resources of Ukraine to generate electricity.

Солнечное излучение исходит от источника с температурой около 6273 К и является первичным источником энергии, что позволяет преобразовывать его в электроэнергию с относительно высоким КПД. Для реализации этого направления следует решить ряд технических вопросов, связанных с нестабильностью энергопоступления и относительно малой плотностью солнечного потока: за пределами атмосферы 1400 кВт/км², на поверхности Земли в ясный день около 1000 кВт/км². Эти показатели солнечного излучения создают трудности в разработке эффективных энерготехнологических комплексов, поскольку требуется большая площадь покрытия фотопреобразующими элементами с последующим аккумулированием энергии. В результате, стоимость гелиокомплексов оказывается высокой, а это снижает их конкурентоспособность по отношению к традиционным энергоустановкам, использующим ископаемое углеводородное топливо. Солнечная энергетика является экологически чистой, то есть такой, что не оказывает вредного воздействия на окружающую среду.

\section{Фотоэлектрические преобразователи}

(ФЭП). В настоящее время в разных странах активно используют фотоэлектрические преобразователи (ФЭП). 90\% рынка — это фотоэлектрические преобразователи на основе поли - и монокристаллического кремния с КПД 15-17 \%. Солнечные фотоэлементы уже сегодня находят свое специфическое применение. Они практически незаменимы в качестве источника электрического потенциала на космических станциях, спутниках и автоматических межпланетных кораблях, а в быту их используют, для питания сетей в не электрифицированных районах для маломощных потребителей.

В настоящее время электроэнергию, получаемую от ФЭП, следует рассматривать, как возможность автономного, резервного снабжения потребителей на случай отказа системы централизованного электроснабжения. Это предполагает разработку и создание ЭТК небольшой мощности, в состав которого входят аккумуляторные батареи для электроснабжения в темное время суток. Если у потребителя существует необходимость иметь переменное напряжение, то в этот 
комплекс должен быть включён инверторпреобразователь постоянного напряжения в переменное [2-4]. Все ЭТК на основе фотоэлектрических преобразователей можно разделить на два типа: автономные и сетевые (соединенные с централизованной электрической сетью). ЭТК второго типа отдают излишки энергии в сеть, которая служит резервной при возникновении её дефицита. Типовая автономная система состоит из набора ФЭПов, размещенных на земле или на крыше, аккумуляторных батарей (АКБ) в качестве буферного накопления электроэнергии, контроллера разряда - заряда аккумуляторов, соединительных кабелей. Приоритетным направлением в разработке автономного ЭТК следует считать замену аккумуляторных батарей на буферное накопление водорода, полученного электролизным способом [5-6]. Для выработки электроэнергии водород предполагается либо сжигать в ДВС, либо электрохимически окислять в топливных элементах. Последнему подходу отдается предпочтение, вследствие более высокой энергоэффективности, компактности и удобства эксплуатации электрохимических энергоустановок [7-8].

Использование электролизёра высокого давления в составе энергетического комплекса. В качестве инновационных научнотехнических разработок, которые могут быть реализованы с максимальной экономической эффективностью, можно выделить проекты с применением водородных технологий, которые направлены на вовлечение энергии солнца в инфраструктуру энерготехнологических комплексов, располагающихся в зонах с высоким потенциалом солнечной радиации [7].

Современный уровень водородных технологий, которые реализуются в электрохимических установках, разработанных в Институте проблем машиностроения им. А. Н. Подгорного Национальной академии наук Украины (ИПМаш НАН Украины), позволяет производить и накапливать водород под высоким давлением [8-13].

В процессе проведенных исследований сформированы принципы научно-технического развития электрохимических водородных систем и предложены пути оптимизации их работы на нестационарных режимах, характерных для реальных условий эксплуатации энерготехнологических комплексов на базе СЭС.
В известных моделях электролизеров снижение энергозатрат достигается путем использования редкоземельных металлов платиновой группы в качестве катализаторов электрохимического процесса на поверхности электродов [1417]. Это, в свою очередь, приводит к удорожанию оборудования, повышению требований к его обслуживанию, уменьшению ресурса эксплуатации. Указанные недостатки могут быть устранены путем реализации инновационной технологии электрохимической генерации водорода, основанной на применении в качестве электродных материалов металлов с переменной валентностью, химически взаимодействующих с кислородом и водородом, образующимися в процессе разложения воды.

Предлагаемая технология производства водорода высокого давления [10, 12-16] состоит из двух полуциклов, периодически чередующихся окислительных и восстановительных реакций с участием активной массы газопоглощающего электрода.

Процесс генерации водорода начинается с подачи на пассивный (газовыделяющий) электрод отрицательного потенциала. На этом этапе активный (газопоглощающий) электрод выступает в качестве анода. Реакция разложения воды происходит с одновременным выделением $\mathrm{H}_{2}$ и $\mathrm{O}_{2}$, но при этом водород выделяется на газовыделяющем электроде в газообразном виде, а кислород химически связывается газопоглощающим электродом (накапливается в виде химического соединения). Питание электроэнергией электролизной ячейки (рис. 2) синхронизировано с электромеханическим переключателем потока, в результате чего $\mathrm{H}_{2}$ выделяется и заполняет только водородную магистраль, не смешиваясь с $\mathrm{O}_{2}$. Первичная очистка от паров электролита происходит в сепараторе, который выполняет функцию разделения газожидкостного потока на составные компоненты газ и жидкость. Электрохимическая реакция разложения воды протекает с ростом напряжения на катодно-анодной паре в процессе генерации газов. Управление электрохимическими процессами осуществляется на основании данных об изменении вольтамперных характеристик процесса, установленных экспериментальным путем и используемых в системе автоматического контроля параметров, обеспечивающего подачу газожидкостной смеси в соответствующую магистраль. 


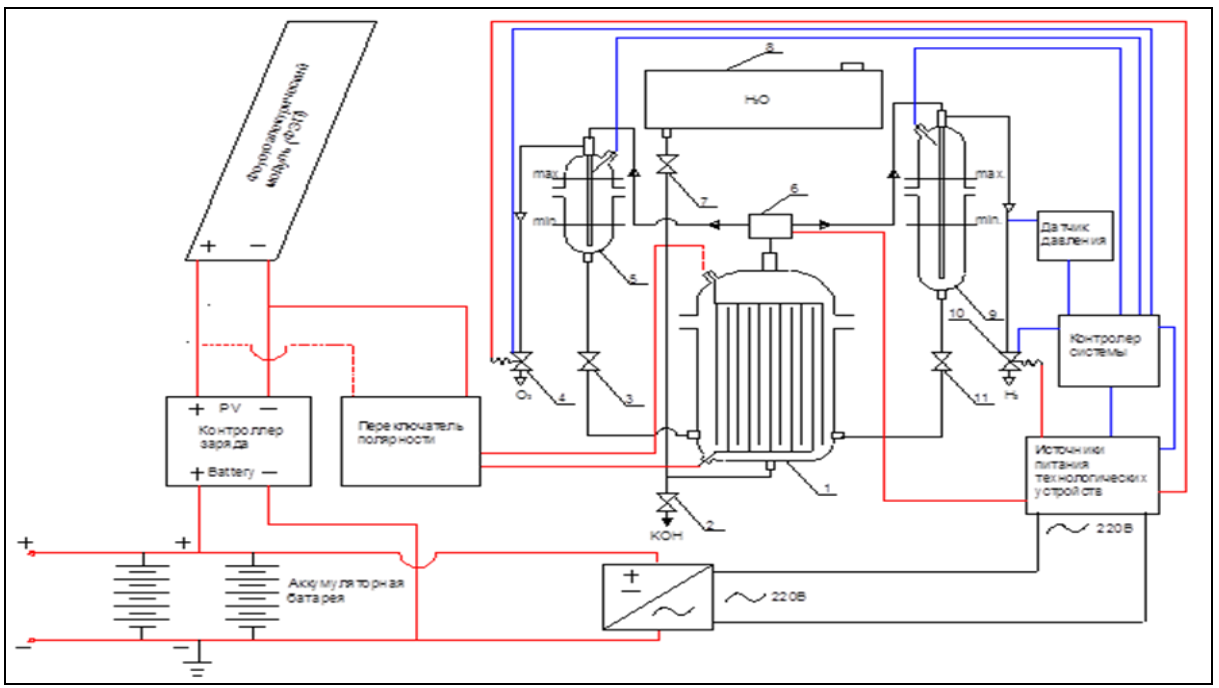

Рис. 2. Принципиальная схема энерготехнологического комплекса: 1 - электрохимическая ячейка; 2 - кран слива электролита (КОН) с гидравлической системы электролизера; 3, 11 - кран обратной связи кислородного и водородного сепараторов; 4 - кран с электромеханическим приводом для автоматического сброса кислорода в систему хранения; 5 -

кислородный сепаратор; 6 - электромеханический переключатель газожидкостного потока; 7 - кран заполнения гидравлической системы электролизера электролитом; 8 - технологический бак хранения $\mathrm{H}_{2} \mathrm{O}$; 9 - водородный сепаратор; 10 - кран с электромеханическим приводом для автоматического сброса водорода в систему хранения.

Fig. 2. Schematic diagram of the energy technology complex: 1 - electrochemical cell; 2 - electrolyte drain valve (KOH) from the hydraulic system of the electrolyzer; 3, 11 - feedback valve of oxygen and hydrogen separators; 4 - crane with an electromechanical drive for automatic discharge of oxygen into the storage system; 5 - oxygen separator; 6 - electromechanical switch of gas-liquid flow; 7 - tap filling the hydraulic system of the electrolyzer with electrolyte; 8 - technological storage tank $\mathrm{H}_{2} \mathrm{O}$;

9 - hydrogen separator; 10 - crane with an electromechanical drive for automatic discharge of hydrogen into the storage system.

При достижении порогового напряжения в 1,2В осуществляется переключение полярности с одновременным включением электромеханического переключателя газожидкостного потока, в результате чего пассивный электрод становится анодом, а активный электрод становится катодом.

На пассивном электроде происходит выделение газообразного кислорода, а на катоде идет восстановление водородом активной массы газопоглощающего электрода (рис.3).

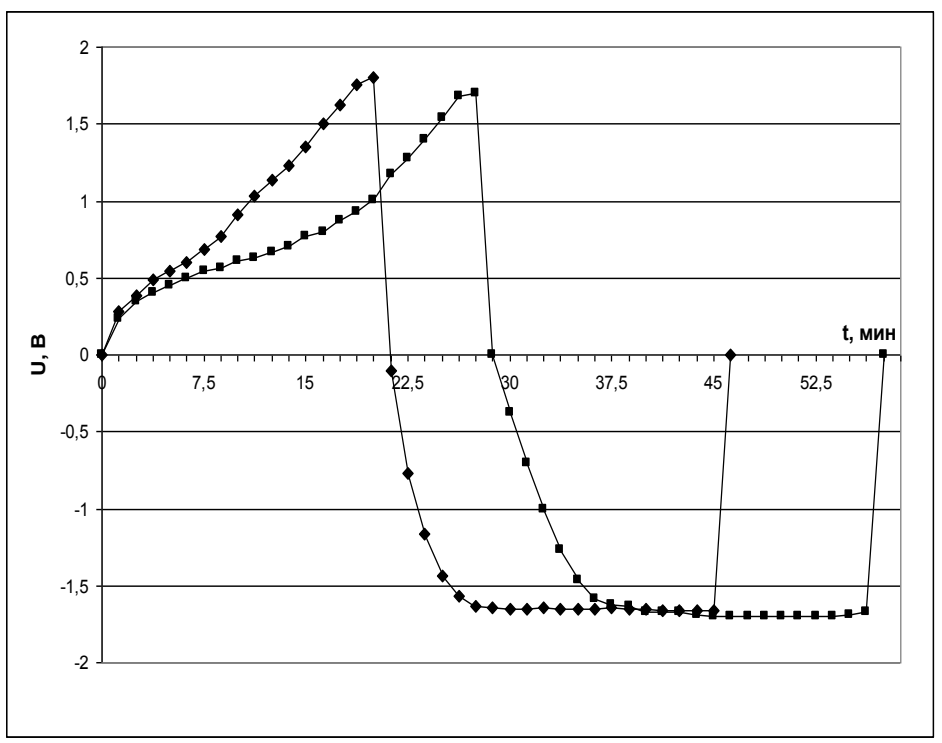

Рис. 3. Циклограмма изменения напряжения выделения водорода и кислорода при электролизе. Плотность тока: - - I = 0,015 A/ $\mathrm{cm}^{2} ; \diamond-I=0,03 \mathrm{~A} / \mathrm{cm}^{2}$.

Fig. 3. The sequence of changes in the voltage of hydrogen and oxygen evolution during electrolysis. Current density:

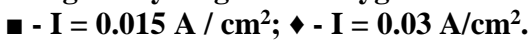


При достижении пороговой величины напряжения в 1,6 В происходит переключение полярности электродов, цикл повторяется.

Использование в качестве газопоглощающего электрода материала с переменной валентностью (например губчатого железа), химически связывающего кислород (рис. 3), соответствует реакции:

$$
\mathrm{Fe}+2 \mathrm{OH}^{-}<\mathrm{Fe}(\mathrm{OH})_{2}^{-}+2 \mathrm{e} .
$$

При длительной работе активной массы электрода происходит более глубокая проработка электродной массы:

$$
\mathrm{Fe}(\mathrm{OH})_{2}+\mathrm{OH}^{-}<=>\mathrm{Fe}(\mathrm{OH})_{3}{ }^{-}+\mathrm{e} .
$$

Область циклограммы изменения электродного потенциала при электрохимическом получении водорода и кислорода на полуцикле выделения $\mathrm{H}_{2}$ (рис. 4) соответствует переходу $\mathrm{Fe}(\mathrm{II})$ в $\mathrm{Fe}(\mathrm{III})$, а полуцикл выделения $\mathrm{O}_{2}$ соответствует электрохимическому восстановлению гидроксидов железа.

Для снижения затрат электроэнергии, используемой для реализации процесса генерации водорода, необходима оптимизация режимов работы электрохимической ячейки. Одним из методов, позволяющим снизить удельные затраты электроэнергии на производство водорода высокого давления, является управляемое ограничение порогового значения напряжения в электрохимической реакции, соответствующее пологому участку вольтамперной характеристики (рис. 3).

Экспериментальные характеристики производительности ЭВД представлены на рис. 4.

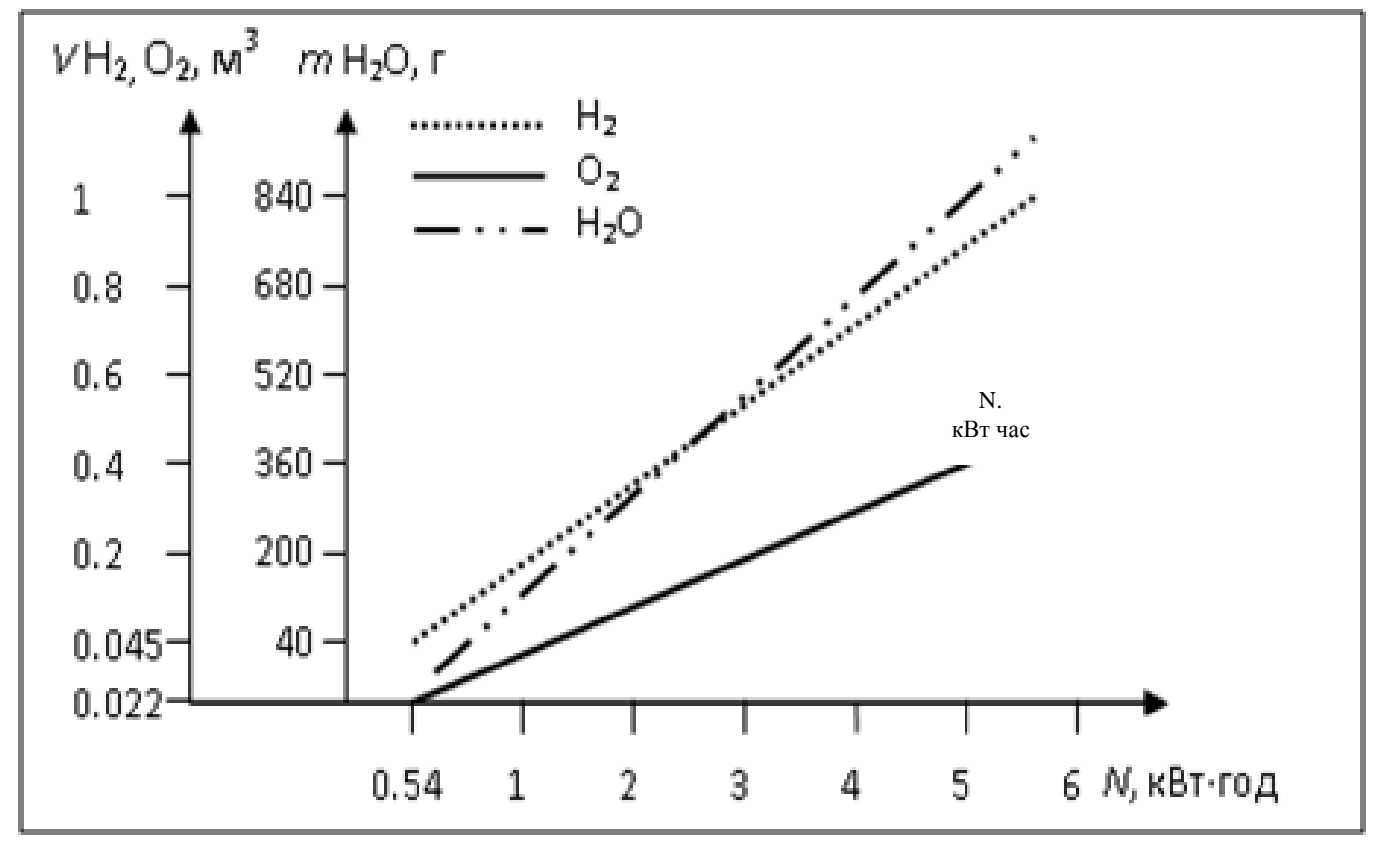

Рис. 4. Экспериментальные характеристики электролизёра.

Fig. 4. Experimental characteristics of the electrolyzer.

С целью решения энергоэкологических вопросов Украины предлагается расширить использование возобновляемых видов энергии путем создания солнечных водородных заправочных станций (СВ3С) на базе новейших технологий для обеспечения автомототранспорта экологически чистым топливом - водородом, схема представлена на рис. 5. 


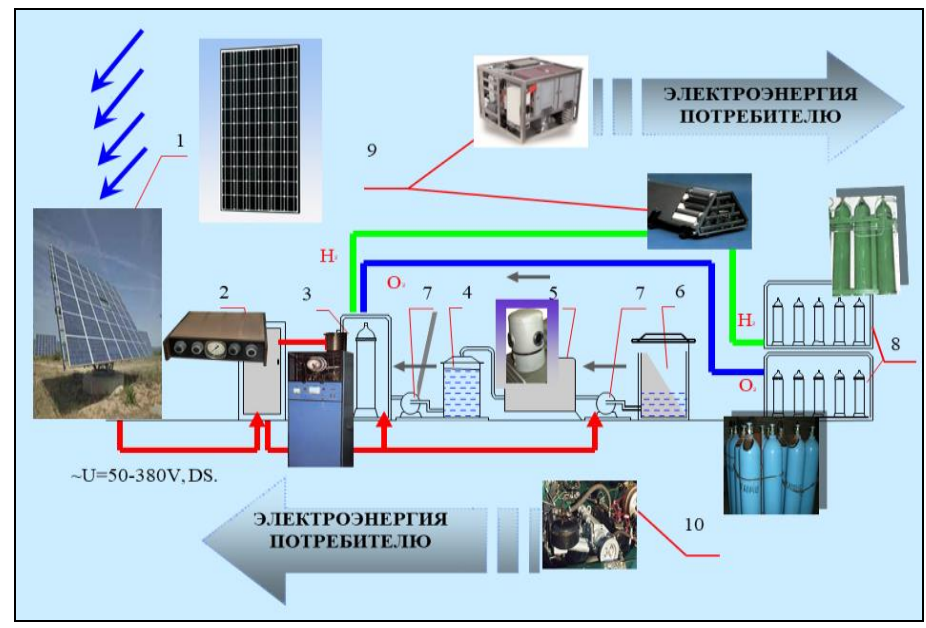

Рис. 5. Принципиальная схема автономного солнечно водородного энерготехнологического комплекса для заправки автотранспорта: 1 - фотоэлектрический преобразователь (ФЭП); 2 - система электропитания и управления; 3 электролизер высокого давления; 4-бак опресненной воды; 5 -опреснительный блок; 6 - бак исходной воды; 7 -насос; 8 баллоны для коммерческой реализации газов; 9, -металлогидридные модули для длительного хранения и сжстия водорода, топливные элементы; 10 - двигатели внутреннего сгорания (ДВС).

Fig. 5. Schematic diagram of an autonomous solar-hydrogen energy-technological complex for refuel ingvehicles: 1 photoelectric converter (PEC); 2 - power supply and control system; 3 - high pressure electrolyzer; 4-desalinated water tank; 5 desalination unit; 6 - source water tank; 7 - pump; 8 - cylinders for the commercial sale of gases; 9, - metal hydride modules for long-term storage and compression of hydrogen, fuel cells; 10 - internal combustion engines (ICE).

Исследования режимных и энергетических характеристик оборудования, которое было разработано для использования в технологических схемах СВЗС, позволили определить основные показатели работы установки в зависимости от геоклиматических условий эксплуатации. Результаты проведенных экспериментальных исследований относительно зависимости затрат электроэнергии при производстве $\mathrm{H}_{2}$ и $\mathrm{O}_{2}$ приведены в таблице.

Таблица. Основные характеристики СВЗС с водородным накопителем энергии при различных режимах эксплуатации ЭВД.

Table. The main characteristics of SHFS with a hydrogen energy storage device under various operating conditions EHP.

\begin{tabular}{|c|c|c|c|c|c|}
\hline \multirow{2}{*}{$\begin{array}{l}\text { Основные } \\
\text { характеристики } \\
\text { СВЗС }\end{array}$} & \multicolumn{5}{|c|}{ Режимы работы ЭВД } \\
\hline & $20 \%$ & $40 \%$ & $60 \%$ & $80 \%$ & $100 \%$ \\
\hline $\begin{array}{l}\text { Расход } \\
\text { электроэнергии, } \\
(\text { кВт·ч) }\end{array}$ & 40 & 80 & 120 & 160 & 200 \\
\hline $\begin{array}{l}\text { Расход } \\
\text { дистиллята, (кг) }\end{array}$ & 8 & 16,5 & 24,7 & 32,9 & 41,2 \\
\hline $\mathrm{H}_{2},\left(\mathrm{M}^{3}\right)$ & 9,7 & 19,5 & 29,2 & 39,0 & 48,8 \\
\hline $\mathrm{O}_{2},\left(\mathrm{M}^{3}\right)$ & 4,8 & 9,76 & 14,3 & 19,5 & 24,9 \\
\hline
\end{tabular}

Топливозаправочные станции, которые построены по разработанной схеме, могут составить конкуренцию зарубежным аналогам, где водород получают из бытового газа [18-20].

Применение в составе топливозаправочного гелиоэнергетического комплекса оригинальной электролизной технологии, по сравнению с традиционными электролизерами, обеспечивает высокую эффективность отбора мощности, надежность и безопасность эксплуатации.

Важной составляющей обеспечения надежной и эффективной работы энерготехнологического комплекса является синхронизация работы ФЭП и системы генерации газов. Полученные данные о конструктивных решениях электролизной техники и особенностях ее эксплуатации в технологических схемах позволили разработать оригинальный алгоритм управления основными элементами и создать техническую базу для его реализации.

Особенности подключения солнечных батарей в составе энерготехнологического комплекса. Поскольку работа энергоустановки определяется непостоянством энергопоступления, выбор основных параметров комплекса (производительность электрохимического генератора водорода и кислорода высокого давления, параметры хранения водорода) определяется с учетом региона и расположения энергоустановки.

Для технического решения этого вопроса рассмотрены схемы с параллельным и непосредственным подключением ЭВД в качестве буферного накопителя энергии.

Основными недостатками схемы ЭТК с последовательным подключением электролизёра высокого давления являются снижение КПД пре- 
образования энергии и снижение надежности системы в целом за счет включения промежуточных элементов энерготехнологической схемы (рис. 6, а). Схема ЭТК с непосредственным подключением исключает промежуточные элементы. ЭВД напрямую подключён к ФЭП (рис.6, б), что существенно повышает КПД отбора мощности, генерируемой фотоэлектрическим преобразователем, и передачу ее без потерь на ЭВД с последующим буферным накоплением водорода в качестве вторичного энергоносителя.

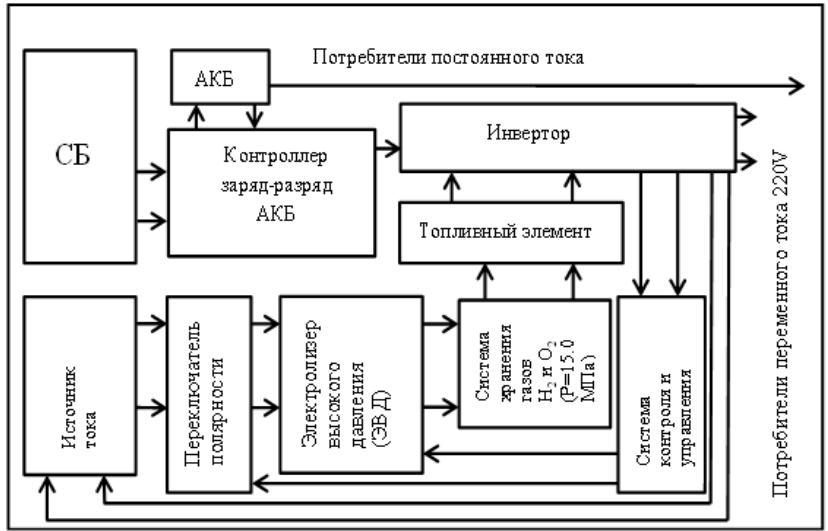

(a)

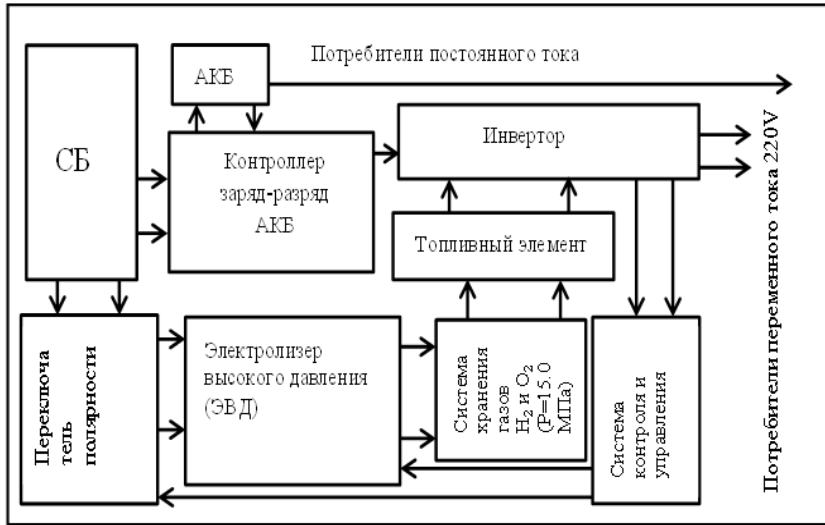

(б)

Рис. 6. Схемы автономных энерготехнологических комплексов с использованием генераторов водорода в качестве буферного накопителя энергии: $a$ - схема ЭТК с последовательным подключением электролизёра высокого давления в качестве буферного накопителя энергии; б - схема ЭТК с непосредственным подключением ЭВД водорода высокого давления в качестве буферного накопителя энергии.

Fig. 6. Schemes of autonomous energy-technological complexes using hydrogen generators as a buffer energy storage: $a$ - ETK circuit with a serial connection of a high pressure electrolyzer as a buffer energy storage device; $b$ - ETK scheme with direct connection of high pressure hydrogen electric power as a buffer energy storage.

Гелиоэнергетическая установка предназначена для преобразования энергии солнца в экологически чистый энергоноситель - водород, который структурно вписан в схему СЭС и обеспечивает решение проблемы бесперебойной подачи электрической энергии потребителю.

Выводы. Исследованы особенности создания солнечных водородных заправочных станций на территории Украины для обеспечения автотранспорта экологически чистым топливом водородом.

Рассмотрено включение в технологическую схему ЭТК буферной системы накопления водорода для обеспечения бесперебойного энергоснабжения при работе комплекса как в нестационарных режимах, так и в случае аварийной остановки.

Включение в состав энергетического комплекса инновационной электролизной технологии обеспечивает следующие преимущества:

- снижение на 10-15 \% энергозатрат по сравнению с существующими электролизными системами (удельное энергопотребление составляет 3,8-4,1 кВт·ч);

- ограничение давления генерируемых газов связано с прочностью элементов конструкции ЭВД;
- повышение надежности и безопасности эксплуатации системы обеспечивается алгоритмом управления и отсутствием разделительных мембран;

- в ЭВД не применяются редкоземельные металлы платиновой группы в качестве катализатора электрохимических процессов, что существенно удешевляет производственный процесс и снижает требования к его организации.

1. Сиволапов В., Гузь М., Новицький А., Марченко В. Потенціал відновлюваних джерел енергії в Україні. Agroexpert. 2016. Том. 12. № 101. С. 74-77.

2. Züttel A., Remhof A., Borgschulte A., Friedrichs, $O$. Hydrogen: the future energy carrier. Philosophical Transactions of the Royal Society A: Mathematical, Physical and Engineering Sciences. 2010. Vol. 368. № 1923. Pp. 3329- 3342.

3. Sherif S.A., Barbir F., Veziroglu T. N. Wind energy and the hydrogen economy-review of the technology. Solar energy. 2005. Vol. 78. №5. Pp.647-660.

4. Schlapbach L. Technology: Hydrogen-fuelled vehicles. Nature. 2009. Vol. 460. № 7257. Pp. 809-811.

5. Зипунников Н.Н., Трошенькин В.Б. Состояние разработок по исследованию процесса и конструирования оборудования получения водорода из воды с использованием сплавов. Вісник НТУ. 2008. № 12. C. 51-55. 
6. Matsevytyi Y., Chorna N., Shevchenko A. Development of a Perspective Metal Hydride Energy Accumulation System Based on Fuel Cells for Wind Energetics. Journal of Mechanical Engineering. 2019. Vol. 22. № 4. Pp. 4852. doi: https://doi.org/10.15407/pmach2019.04.048

7. Clarke R. E., Giddey S., Ciacchi F. T., Badwal S. P. S., Paul B., Andrews J. Direct coupling of an electrolyser to a solar PV system for generating hydrogen. International Journal of Hydrogen Energy. 2009. Vol. 34. № 6. Pp. 2531-2542.

8. Kunusch C., Puleston P. F., Mayosky M. A., Riera $J$. Sliding mode strategy for PEM fuel cells stacks breathing control using a super-twisting algorithm. IEEE Transactions on Control Systems Technology. 2009. Vol. 17. № 1. Pp. 167-174.

9. Mazloomi K., Gomes C. Hydrogen as an energy carrier: Prospects and challenges. Renew. Sustain. Energy Rev. 2012. Vol. 16. Pp. 3024-3033.

10. Sharma S., Ghoshal S.K. Hydrogen the future transportation fuel: From production to applications. Renew. Sustain. Energy Rev. 2015. Vol. 43. Pp. 1151-1158.

11. Соловей. В.В., Шевченко А.А., Котенко А.Л., Макаров O.O. Пристрій для одержання водню високого тиску. Пат. № 103681. Україна, МПК6 С 25В 1/12. № 2011 15332. Заявл. 26.12.2011. Опубл. 10.07.2013. Бюл. № 21. 4 c.

12. Шевченко A.A. Использование ЭЛАЭЛов в автономных энергоустановках, характеризующихся неравномерностью энергопоступления. Авиационнокосмическая техника и технология: Сб. научн. тр. Харьков. Гос. аэрокосмический ун-т “ХАИ”. 1999. Вып.13. С. 111-116.

13. Соловей В.В., Жиров А.С., Шевченко А.А. Влияние режимных факторов на эффективность электролизера высокого давления. Совершенствование турбоустановок методами математического и физического моделирования. Сб. научн. трудов. 2003. С. 250254.

14. Solovey V., Kozak L., Shevchenko A., Zipunnikov $M$., Campbell R., Seamon F. Hydrogen technology of energy storage making use of windpower potential. Problemy Mashinostroyeniya - Journal of Mechanical Engineering. 2017. Vol. 20. № 1. Pp. 62-68. doi: https://doi.org/10.17721/fujcV6I2P73-79.

15. Solovei V., Kotenko A., Vorobiova I., Shevchenko A., Zipunnikov M. Basic operation principles and control algorithm for a high-pressure membrane-less electrolyser. Journal of Mechanical Engineering. 2018. Vol. 21. № 4. Pp. 57-63.

doi: https://doi.org/10.15407/pmach2018.04.057.

16. Solovey V., Khiem N. T., Zipunnikov M. M., Shevchenko $A$. Improvement of the Membrane-less Electrolysis Technology for Hydrogen and Oxygen Generation. French-Ukrainian Journal of Chemistry. 2018. Vol. 6. № 2. Pp. 73-79.

doi: https://doi.org/10.17721/fujcV6I2P73-79.

17. Solovey V., Zipunnikov N., Shevchenko A., Vorobjova I., Kotenko A. Energy Effective Membrane-less Technology for High Pressure Hydrogen Electro-chemical Generation. French-Ukrainian Journal of Chemistry. 2018. Vol. 6. № 1. Pp. 151-156. doi: https://doi.org/10.17721/fujcV6I1P151-156.

18 Shevchenko A., Zipunnikov M., Kotenko A., Vorobiova,I., Semykin $V$. Study of the Influence of Operating Conditions on High Pressure Electrolyzer Efficiency. Journal of Mechanical Engineering. 2019.Vol. 22. № 4. Pp. 53-60.

doi: https://doi.org/10.15407/pmach2019.04.053.

19. Phillips R., Dunnill C.W. Zero gap alkaline electrolysis cell design for renewable energy storage as hydrogen gas. RSC Adv. 2016. Vol. 6. Pp. 100643100651 .

20. Phillips R., Edwards A., Rome B., Jones D.R., Dunnill C.W. Minimising the ohmic resistance of an alkaline electrolysis cell through effective cell design. Int. J. Hydrogen Energy 2017. Vol. 42. Pp. 23986-23994.

\section{REFERENCES}

1. Sivolapov V., Guz A., Novitsky M., Marchenko V. Potentsial vidnovlyuvanykh dzherel enerhiyi v Ukrayini. [Potential of the latest generation of energy in Ukraine]. Agroexpert. 2016. Vol. 12. № 101. Pp. 74-77. [in Ukrainian].

2. Züttel A., Remhof A., Borgschulte A., Friedrichs, $O$. Hydrogen: the future energy carrier. Philosophical Transactions of the Royal Society A: Mathematical, Physical and Engineering Sciences. 2010. Vol. 368. № 1923. Pp. 3329- 3342. [in English].

3. Sherif S.A., Barbir F., Veziroglu T.N. Wind energy and the hydrogen economy-review of the technology. Solar energy. 2005. Vol. 78. № 5. Pp. 647-660. [in English].

4. Schlapbach L. Technology: Hydrogen-fuelled vehicles. Nature. 2009. Vol. 460. № 7257. Pp. 809-811. [in English].

5. Troshenkin, V.B., Zippunikov N.N. Sostoyaniye razrabotok po issledovaniyu protsessa i konstruirovaniya oborudovaniya polucheniya vodoroda iz vody $s$ ispol'zovaniyem splavov. [State of developments on the study of the process and design of equipment for the production of hydrogen from water using alloys]. Vestnik NTU "KhPI". 2008. Vol. 12. Pp. 51-55. [in Russian].

6. Matsevytyi $Y$., Chorna N., Shevchenko A. Development of a Perspective Metal Hydride Energy Accumulation System Based on Fuel Cells for Wind Energetics. Journal of Mechanical Engineering. 2019. Vol. 22. № 4. Pp. 48-52. doi: https://doi.org/10.15407/pmach2019.04.048 [in English].

7. Clarke R. E., Giddey S., Ciacchi F. T., Badwal S. P. S., Paul B., Andrews J. Direct coupling of an electrolyser to a solar PV system for generating hydrogen. International Journal of Hydrogen Energy. 2009. Vol. 34. № 6. Pp. 2531-2542. [in English].

8. Kunusch C., Puleston P. F., Mayosky M. A., Riera $J$. Sliding mode strategy for PEM fuel cells stacks breathing control using a super-twisting algorithm. IEEE Transactions on Control Systems Technology. 2009. Vol. 17. № 1. Pp. 167-174. [in English].

9. Mazloomi K., Gomes C. Hydrogen as an energy carrier: Prospects and challenges. Renew. Sustain. Energy Rev. 2012. Vol. 16. Pp. 3024-3033. [in English]. 
10. Sharma S., Ghoshal S.K. Hydrogen the future transportation fuel: From production to applications. Renew. Sustain. Energy Rev. 2015. Vol. 43. Pp. 11511158. [in English].

11. Solovey V.V., Shevchenko A.A., Kotenko A.L., Makarov O.O. 3013. The Device for Generation Highpressure Hydrogen. Patent of Ukraine № 103681 МПК C25B 1/12, C25B 1/03. Made public on November 11. 2013. Bulletin No. 21. [in Ukrainian].

12. Shevchenko A.A. Ispolzovaniye ELAELov v avtonomnykh energoustanovkakh, kharakterizuyushchikhsya neravnomernostyu energopostupleniya. [The use of ELAELs in autonomous power plants characterized by uneven energy supply]. Aviats.-kosm.tekhnika i tekhnologiya. Aerospace Technic and Technology. Kharkov. Kharkiv Aerospace University "KhAI".1999. Vol. 13. Pp. 111-116. [in Russian].

13. Solovey V.V., Zhirov A.S., Shevchenko A.A. Vliyaniye rezhimnykh faktorov na effektivnost elektrolizera vysokogo davleniya. Sovershenstvovaniye turboustanovok metodami matematicheskogo i fizicheskogo modelirovaniya. [The influence of regime factors on the efficiency of a high-pressure cell. Improvement of turbine installations by methods of mathematical and physical modeling]. Sb. nauch. tr. 2003. Pp. 250-254. [in Russian].

14. Solovey V., Kozak L., Shevchenko A., Zipunnikov M., Campbell R., Seamon F. Hydrogen technology of energy storage making use of windpower potential. Problemy Mashinostroyeniya - Journal of Mechanical Engineering. 2017. Vol. 20. № 1. Pp. 62-68. doi: https://doi.org/10.17721/fujcV6I2P73-79. [in English].

15. Solovei V., Kotenko A., Vorobiova I., Shevchenko A., Zipunnikov M. Basic operation principles and control algorithm for a high-pressure membrane-less electrolyser. Journal of Mechanical Engineering. 2018. Vol. 21. № 4. Pp. 57-63. doi: https://doi.org/10.15407/pmach2018.04.057. [in English].

16. Solovey V., Khiem N. T., Zipunnikov M. M. Shevchenko A. Improvement of the Membrane-less Electrolysis Technology for Hydrogen and Oxygen Generation. French-Ukrainian Journal of Chemistry. 2018. Vol. 6. № $2 . \quad$ Pp. 73-79. doi: https://doi.org/10.17721/fujcV6I2P73-79. [in English].

17. Solovey V., Zipunnikov N., Shevchenko A., Vorobjova I., Kotenko A. Energy Effective Membrane-less Technology for High Pressure Hydrogen Electro-chemical Generation. French-Ukrainian Journal of Chemistry. 2018. Vol. 6. № 1. Pp. 151-156. doi: https://doi.org/10.17721/fujcV6I1P151-156. [in English].

18 Shevchenko A., Zipunnikov M., Kotenko A., Vorobiova,I., Semykin V. Study of the Influence of Operating Conditions on High Pressure Electrolyzer Efficiency. Journal of Mechanical Engineering. 2019.
Vol. 22. № 4. Pp. 53-60. doi: https://doi.org/10.15407/pmach2019.04.053. [in English].

19. Phillips R., Dunnill C.W. Zero gap alkaline electrolysis cell design for renewable energy storage as hydrogen gas. RSC Adv. 2016. Vol. 6. Pp. 100643100651. [in English].

20. Phillips R., Edwards A., Rome B., Jones D.R., Dunnill C.W. Minimising the ohmic resistance of an alkaline electrolysis cell through effective cell design. Int. J. Hydrogen Energy 2017. Vol. 42. Pp. 23986-23994. [in English].

\section{СТВОРЕННЯ АВТОНОМНИХ I МЕРЕЖЕВИХ ЕНЕРГОТЕХНОЛОГІЧНИХ КОМПЛЕКСІВ 3 ВОДНЕВИМ НАКОПИЧУВАЧЕМ ЕНЕРГІЇ}

А.А. Шевченко, головний інженер відділу водневої енергетики

Інститут проблем машинобудування ім. А.М. Підгорного НАН України,

61046, вул. Пожарського 2/10, м. Харків, Україна.

У статті проведено аналіз енергетичних можливостей альтернативних джерел Украӥни. Розглянуто проекти із застосуванням водневих технологій, спрямованих на залучення енергї сония в інфраструктуру енерготехнологічних комплексів, зокрема систем для заправки автомобільного транспорту, розташованих в зонах з високим потенціалом сонячної радіаціï. При експлуатації автономних водневих заправочных станиій, що використовують як джерело енергї сонячну енергетичну станцію (СЕС), досить ймовірне виникнення нештатних ситуацій, зумовлених або припиненням енергопостачання (внаслідок похмурої погоди), або з аварійним виходом з ладу окремих елементів системи. В иьому випадку потрібно забезпечити виведення $\dddot{̈} з$ експлуатації без втрати технологічних можливостей (працездатності). 3 иісю метою необхідно передбачити включення в технологічну схему енерготехнологічного комплексу додатковий елемент, що забезпечує роботу блоку протягом заданого часу, який визначається регламентом його експлуатації. В якості такого елементу запропонована буферна система на основі водневого накопичувача енергіі. Сучасний рівень водневих технологій, які реалізуються в електрохімічних установках, розроблених в Інституті проблем машинобудування ім. А. Н. Підгорного Національної академії наук Украӥни (ІПМаш НАН Украӥни), дозволяє виробляти $i$ накопичувати водень під високим тиском, щуо виключає використання компресорної техніки.

Наведено приниипову схему автономного сонячно-водневого енерготехнологічного комплексу для заправки автомобільного транспорту.

Описано особливості підключення сонячних батарей в складі енерготехнологічного комплексу. Бібл. 20, табл. 1, puc. 6.

Ключові слова: альтернативні джерела, енерготехнологічний комплекс, водень, енергія сония, водневий генератор. 